\section{Size Effect in Torsional, failure of Concrete BEAMS}

By Zdeněk P. Bažant,' F. ASCE, and Siddlk Sener²

Aвstanct: The paper examines whether the size effect law for failures due to distributed cracking, recently derived from fracture mechanics arguments, is applicable to torsional failure of unreinforced or longitudinally reinforced concrete beams of rectangular cross section without stirrups. The test data available in the literature are used for this purpose. They confirm that a size effect is present and does not disagree with the size effect law. However, the data range is so narrow and their scatter so large that the precise form of the size effect cannot be identified. A simple, theoretically based formula to take the size effect into account is suggested.

\section{INTRODUCTION}

Although, whenever possible, it is desirable to design concrete structures to fail in a ductile manner, brittle failures cannot be avoided in some well-known situations. While in ductile failures the load remains constant at increasing deformation after the ultimate state is reached, in brittle failures the load decreases after the ultimate state. The phenomenon of load decrease after the peak has a profound effect on the behavior and safety margins of the structure, and its most significant manifestation is perhaps the size effect. Whereas for plastic behavior (assumed in limit analysis) geometrically similar structures of different sizes fail at the same nominal stress level, for brittle behavior, the larger the structure, the smaller is the nominal stress at failure. This property is a consequence of the fact that if the load decreases after the peak, the failure cannot be simultaneous but occurs through propagation of a failure zone across the structure, one part having already failed when another part reaches its peak capacity. In a larger structure, this propagating, nonsimultaneous nature of failure is more marked. In energy terms, the previously failed regions of the structure cause elastic energy to be released into the currently failing regions and thus help to drive the failure. In a larger structure, the energy release available for further propagating the failure is greater, and hence the size effect.

In previous studies $(5,12,9-11)$, the size effect has been analyzed for the diagonal shear failure of concrete beams with longitudinal reinforcement, and both without and with stirrups; for diagonal shear failure of prestressed concrete beams; for punching shear failure; and for beam and ring failures of unreinforced pipes. Another important type of brittle failure is the torsional failure, and for theoretical reasons as well as by analogy with

'Prof. of Civ. Eng., Northwestern Univ., Evanston, IL 60208.

2Visiting Scholar, Northwestern Univ., Evanston, IL 60208; Asst. Prof. on leave from Tech. Univ. Istanbul, Turkey.

Note. Discussion open until March 1, 1988. To extend the closing date one month, a wrilten request must be filed with the ASCE Manager of Journals. The manuscript for this paper was submitted for review and possible publication on November 1, 1986. This paper is part of the Journal of Structural Engineering, Vol. 113. No. 10. October, 1987. OASCE, ISSN 0733-9445/87/0010-2125/\$01.00. Paper No. 21862.

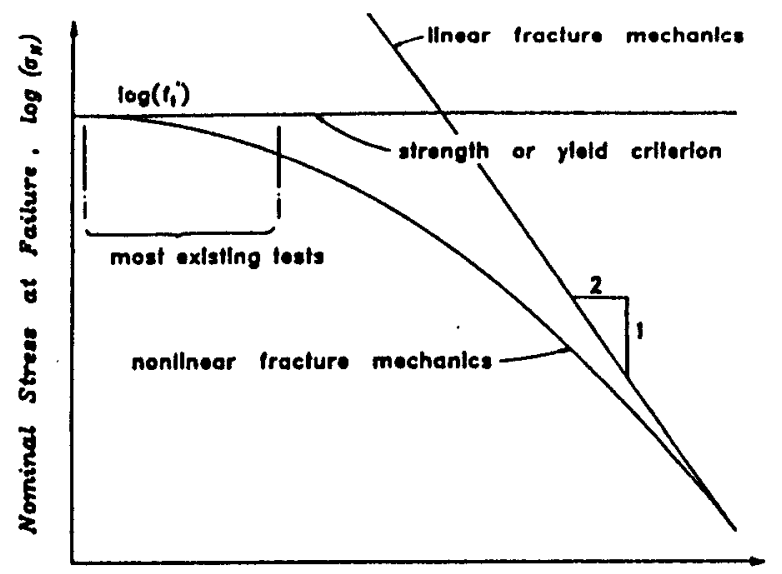

$\log ($ oise d)

FIG. 1. Size Effect Law

the results of previous studies, the existence of the size effect should be expected. The purpose of the present study is to examine this question, drawing on the valuable experimental evidence already documented in the literature $(18,20,23)$. Although there are many other valuable test data on torsion failures $(1,2,15,17,21,22,24,25,28-34)$, they cannot be used in this study because they give no information on the size effect.

\section{Size Effect Law}

The size effect in concrete structures is intermediate between the linear elastic fracture mechanics, for which it is much too strong, and the plastic limit analysis, for which it is absent. As derived by dimensional analysis and similitude arguments $(3,4,7)$, the following approximate size effect law (Fig. 1) appears to be applicable to brittle failures of structures that are made of heterogeneous materials, such as concrete, and are geometrically similar, in either two $(3-5,7)$ or three dimensions $(8)$ :

$\sigma_{N}=B f_{1}^{\prime} \phi(\lambda), \quad \phi(\lambda)=\left(1+\frac{\lambda}{\lambda_{0}}\right)^{-1 / 2}$

in which $f_{t}=$ direct tensile strength of concrete; $B$ and $\lambda_{0}=$ empirical constants depending on the shape of the structure; $\lambda=d / d_{a}=$ relative structure size; $d=$ characteristic dimension of the structure; $d_{a}=$ maximum aggregate size; $\sigma_{N}=$ nominal stress at failure; and $P=$ maximum load of the structure (representing the failure load in a loadcontrolled test). For two dimensions, $\sigma_{N}=P / b d$ where $b=$ structure thickness, while for three dimensions, $\sigma_{N}=P / \mathscr{d}^{2}$. With constant $B$ and $\lambda_{0}$, Eq. $I$ is applicable only to structures that are geometrically similar. However, generalization to different geometrical shapes is possible if the dependence of $B$ and $\lambda_{0}$ on the structure geometry is determined.

Eq. 1 has been derived (3) from the following simplifying, yet apparently quite realistic hypotheses: 
Hypothesis I. The energy release into the front of the cracking zone at the moment of failure depends on the length of the fracture surface at the moment of failure.

Hypothesis II. It also depends on the area of the cracking zone frontal width, which is a constant multiple of the maximum aggregate size $d_{a}$.

Hypothesis III. The failure surfaces which form at the moment of failure in geometrically similar structures of different sizes are also geometrically similar.

Hypothesis IV. The structure fails due to propagation of a well-developed cracking zone rather than at the initiation of cracking.

The last hypothesis is practically always satisfied since the design must normally be such that the failure load be sufficiently higher than the crack initiation load (e.g., according to ACI Standard (14) for bending, it must be 1.25 times higher). Hypothesis IIl is usually also confirmed by tests; in diagonal shear it would be violated if, e.g., the crack inclinations were widely different for beams of various depths, which is not the case. Neither are large differences observed for the inclination of the failure crack in torsion in beams of different sizes.

Hypotheses II and I are supported by various theoretical as well as experimental arguments presented elsewhere (3-8). If only hypothesis were applicable, the resulting size effect would conform to linear elastic fracture mechanics, and if only hypothesis II were applicable, the size effect would be absent, as in plastic limit analysis. These two cases represent the limiting cases of Eq. I. If the structure is very small, then $\lambda / \lambda_{0}$ is negligible compared to 1 , in which case $\sigma_{N}$ is proportional to the strength $f_{i}$. This is the case of plastic limit analysis (or elastic allowable stress design). If the structure is very large, then 1 is negligible compared to $\lambda / \lambda_{0}$, in which case $\sigma_{N}$ is inversely proportional to $\lambda^{1 / 2}$. This is typical of linear elastic fracture mechanics. While most laboratory tests carried out in the past are close to the plastic limit analysis case (negligible $\lambda / \lambda_{0}$ ), real structures are mostly in the transitional case between the limits of plastic limil analysis and linear elastic fracture mechanics.

The approximate size effect law for failures due to distributed cracking (Eq. 1) was previously compared to the available test data on the diagonal shear failure of longitudinally reinforced nonprestressed and prestressed beams available in the literature, as well as the data on beam and ring failures of unreinforced pipes. It was also compared to the results of tests on punching shear failure of slabs of widely different sizes made at Northwestern University (11). These comparisons revealed no disagreements with the size effect law, but because of the large statistical scatter of test data they cannot be said to prove validity of the law. The choice of the size effect law given by Eq. I, as opposed to some other possible empirical formulas, rests on theoretical arguments.

Note also that Eq. $I$ is strictly applicable only to structures made of the same concrete, which requires the maximum aggregate size $d_{n}$ to be the same. As an approximation, Eq. I may apparently be used even when there are small differences in $d_{a}$. When there are large differences in $d_{a}$, a correction term must be introduced into Eq. I $(13,6,8)$.

Note also that the choice of the characteristic dimension $d$ is irrelevant and is strictly a matter of convenience. For example, for diagonal shear failures, $d$ can be chosen as either the beam depth or the beam length. The only consequence is that the value of $B$ in Eq. I will come out to be different for the two choices.

\section{Formula for Torsional Shear Strength}

We now consider rectangular beams with a constant cross section of depth $d$ and width $b$, subjected to torque $T$ (Fig. 2). According to the theory of elasticity, the maximum shear stress, which arises in the middle of the beam depth, may be expressed as

$v_{t}=\frac{1}{a} \frac{T}{b^{2} d}$

in which $\alpha$ is a coefficient given by the elasticity solution and depends on the ratio $b / d$ (it is assumed that $b \leq d$ ). If the design is based on the cracking torque, $v$, must be less than the given cracking stress.

The shear stress at failure may be based on plastic limit analysis, which yields the approximate formula (27):

$v_{u}=\frac{T}{\alpha_{p} b^{2} d}, \quad \alpha_{p}=\frac{1}{2}\left(1-\frac{b}{3 d}\right)$

It may further be considered that the ultimate value of $v$ at failure is proportional to the tensile strength, which itself is proportional to $\sqrt{f_{c}^{\prime}}$, where $f_{c}^{\prime}$ is the standard compression strength of concrete. Thus, the design condition for the ultimate load may be written as $v_{u} \leq k_{1} \sqrt{f^{\prime \prime}}$, where $k_{1}$ is an empirical coefficient to be calibrated by torsional tests of beams. By substituting $T=\alpha v, b^{2} d$ (Eq. 2) into Eq. 3, the condition for the ultimate state $v_{u}=k_{1} \sqrt{f_{c}^{\prime}}$ may be expressed as $v_{t} \leq v_{u}$ where the ultimate torsional shear stress is

$v_{u}=\frac{1}{2 \alpha}\left(1-\frac{b}{3 d}\right) k_{1} \sqrt{f_{c}^{\prime}}$

Although the size effect law was originally derived for two-dimensional similarity, it also applies for three-dimensional similarity (8). Thus it
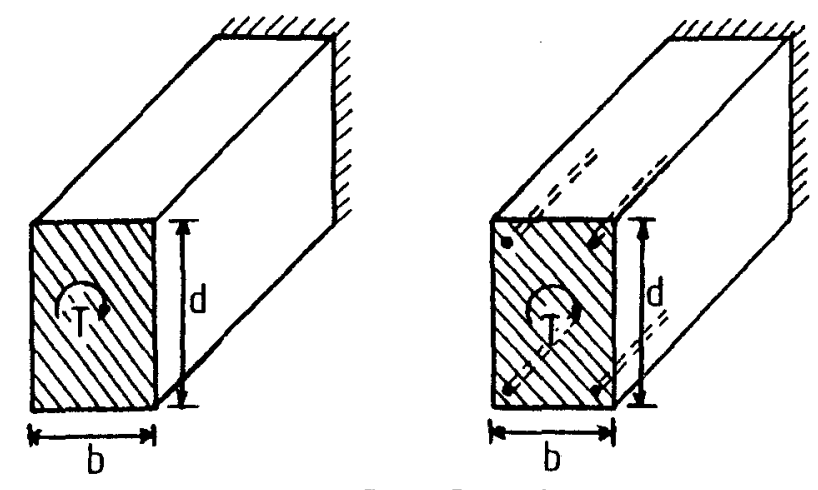

FIG. 2. Beam Geometry 

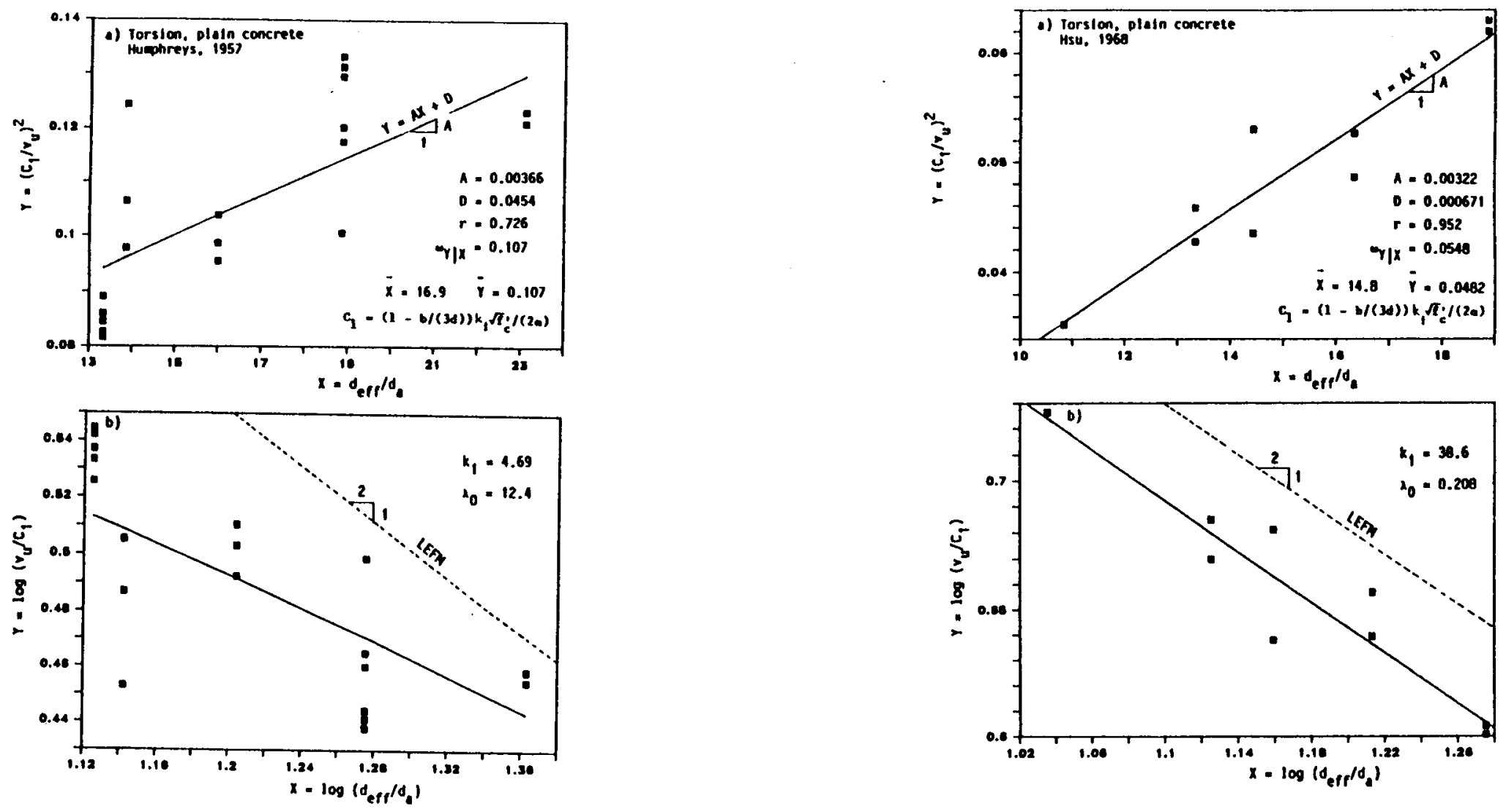

\section{FIG. 3. Size Effect for Plaln Concrete Beams, Humphrey's Data (1957)}

should be applicable to torsional failure which is three-dimensional According to the size effect law (Eq. I), the failure limit given by Eq. 4 should be applicable only for the limiting case of an infinitely small structure for which $\lambda / \lambda_{0}$ is negligible compared to 1, i.e., $\sigma_{N}=B f_{i}^{\prime}, \sigma_{N}$ may be identified with $v_{t}$ and the expression in Eq. 4 corresponds to $B f_{t}^{\prime}$. Thus, it appears that Eq. 4 should be generalized to arbitrary beam depths as follows:

$v_{\mathrm{u}}=C_{1}\left(1+\frac{d_{\mathrm{efr}}}{\lambda_{0} d_{a}}\right)^{-1 / 2}, \quad C_{1}=\frac{1}{2 \alpha}\left(1-\frac{b}{3 d}\right) k_{1} \sqrt{f_{c}^{\prime}}$

in which $d_{\text {eff }}$ represents some suitable measure of the size of the cross section.

We must now decide the proper definition of $d_{\mathrm{eff}}$. The existing data do not suffice for deciding this question empirically. From the mechanics viewpoint we know that the dimension of the shorter side of a rectangular cross section decides the initiation of cracking; however, at ultimate state, stress redistributions occur and the effective size should also depend on
FIG. 4. Size Effect for Plain Concrete Beams, Hsu's Data (1968)

the beatn depth $d$. Therefore, in absence of any more precise information, we select as the effective beam size the expression

$d_{\mathrm{eff}}=\sqrt{b d}$

This expression appeared to yield beller fits of the existing test data than some other alternatives, such as $d_{\mathrm{cff}}=b$ or $d_{\mathrm{eff}}=d$.

The formula in Eq. 5 is intended for both plain concrete beams and beams that have longitudinal reinforcement. According to the current method of limit analysis for torsion of reinforced concrete beams, longitudinal reinforcement, unlike stirrups, has no effect. Indeed, the available test results reveal no systematic difference between the ultimate torques of beams with and without longitudinal bars $(1,2,19,22)$. [The differences between these two cases were generally less than $15 \%(19)$.]

\section{Analysis of Existing Test Data}

The simple form of the size effect (Eq. 1) has the advantage that the formula can be algebraically rearranged to a linear form so that the 

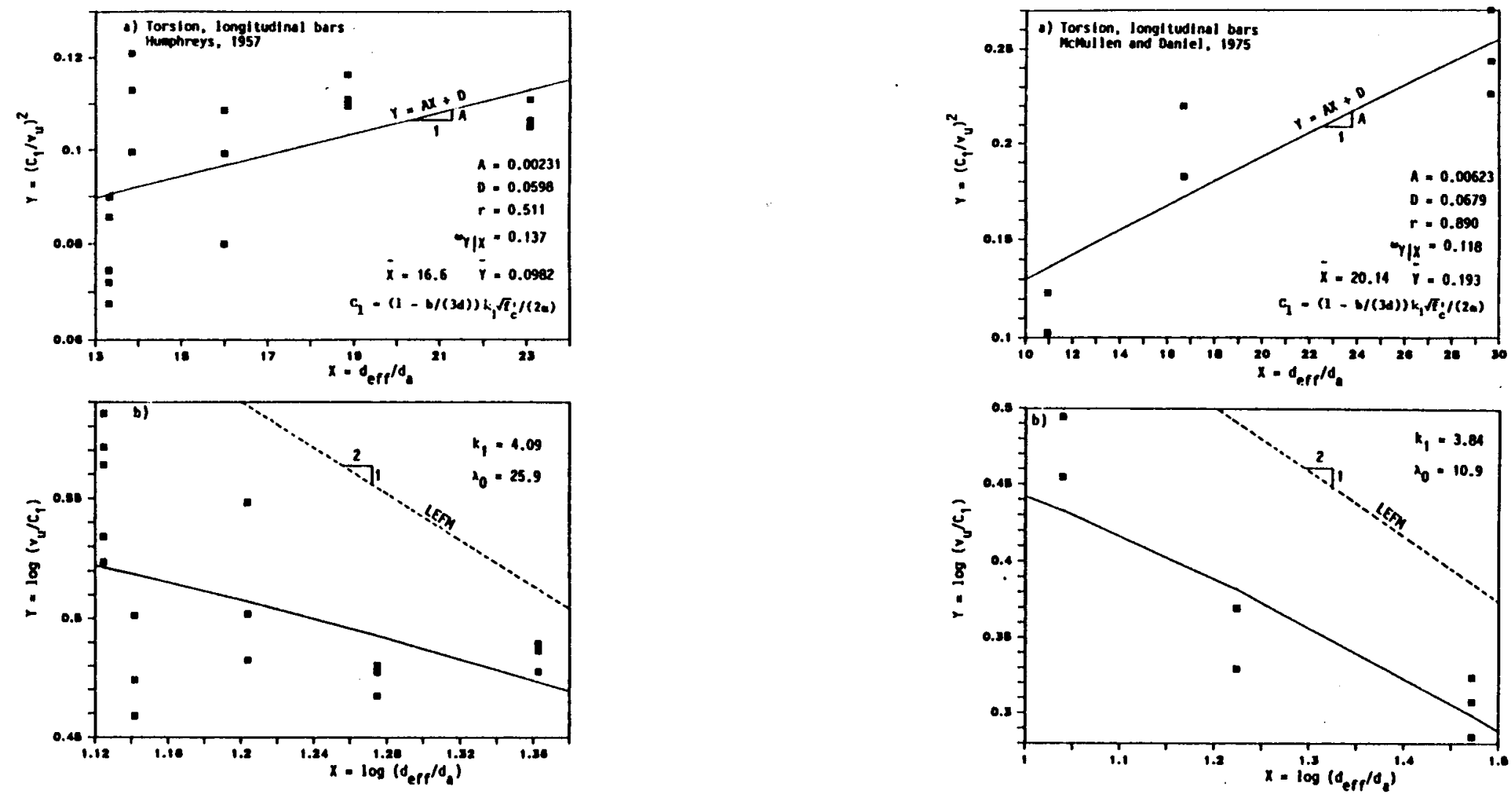

\section{FIG. 5. Slze Effect for Longltudinally Relnforced Beams, Humphrey's Data (1957)}

unknown parameters can be obtained by linear regression. Indeed, Eq. 7 is equivalent to

$\frac{1}{v_{u}^{2}}=\frac{1}{C_{1}^{2}}+\frac{1}{C_{1}^{2}} \frac{d_{\mathrm{efl}}}{\lambda_{0} d_{a}}$

Plotting $1 / v_{u}^{2}$ versus $d_{\text {efl }} / d_{u}$, the data would ideally fall on a straight line of slope $k_{1} / \lambda_{0}$ and a vertical axis intercept $1 / C_{1}^{2}$. The vertical deviations from this straight line, illustrated in Figs. 3a, 4a, 5a and 6a, represent statistical errors.

Numerous test data exist in the literature; however, only a few of them can be used for checking the size effect in torsion, and even those are rather limited in the size range and lack geometrical similarity. Figs. 3-6 show the comparisons with the test data by Humphreys (20), Hsu (18), and McMullen and Daniel (23), which are summarized in Table 1. When the cubic strength $f_{c}$ (in psi) was reported, it was converted to the cylindrical strength $f^{\prime \prime}$ according to the formula (26): $f_{\prime \prime}^{\prime \prime}=[0.76+0.20 \log (f / 2,840)]$ $f_{c}$. Each figure shows the linear regression plot as well as the size effect plot of the logarithm of the normalized nominal stress at failure $v_{n}$ versus
FIG. 6. Size Effect for Longltudinally Relnforced Beams, McMulien and Daniel's Data (1975)

the logarithm of the relative cross section size $d_{e n} / d_{a}$. The parameters of the optimum fits are indicaled in the figures, along with the correlation coefficient $r$, the coefficients of variations of the deviations from the regression line $\omega_{v i x}$, and coordinates $\bar{X}$ and $\bar{Y}$ of the centroids of the data.

The principal observation from the comparisons with these data is that they confirm the existence of the size effect. This is of course not an entirely new conclusion since the existence of the size effect was already pointed out by Hsu (18). The data in the figures do not disagree with the size effect law, but at the same time they are certainly insufficient to prove its validity, because of range limitation and larger scatter.

The main reason for the enormous scatler is the narrowness of the size range of the existing data. At most the sizes of one avaialble data set differ as $1: 2.7$ while for verification and accurate calibration of the size effect law it is probably necessary to have test results for sizes differing at least as 1:8. Of course such tests would be far more expensive than those carried out so far. Another reason for the enormous scatter is the lack of geometrical similarity. The effect of geometrical shape is taken into 
TABLE 1. Test Data from Lilterature Used for Callbration of Present Formula

\begin{tabular}{|c|c|c|c|c|c|}
\hline $\begin{array}{c}\text { Beam } \\
\text { number } \\
\text { (1) }\end{array}$ & $\begin{array}{c}b \\
\text { (in.) } \\
(2)\end{array}$ & $\begin{array}{l}d \\
\text { (in.) } \\
\text { (3) }\end{array}$ & $\begin{array}{c}d_{a} \\
\text { (in.) } \\
\text { (4) }\end{array}$ & $\begin{array}{c}f_{c}^{\prime} \\
\text { (psi) } \\
(5)\end{array}$ & $\begin{array}{c}T_{n} \\
\text { (kip-in.) } \\
\text { (6) }\end{array}$ \\
\hline \multicolumn{6}{|c|}{ (a) Humphreys, R., 1957: Unreinforced Beam } \\
\hline $\begin{array}{l}\text { POA } \\
\text { POB } \\
\text { POC } \\
\text { POD } \\
\text { POE } \\
\text { PROA } \\
\text { PROB } \\
\text { PROC } \\
\text { PRHA } \\
\text { PRHB } \\
\text { PRHC } \\
\text { PSOA } \\
\text { PSOB } \\
\text { PSOC } \\
\text { PTOA } \\
\text { PTOB } \\
\text { PTOC } \\
\text { PUOA } \\
\text { PUOB } \\
\text { PUOC }\end{array}$ & $\begin{array}{r}5 \\
5 \\
5 \\
5 \\
5 \\
10 \\
10 \\
10 \\
5 \\
5 \\
5 \\
5 \\
5 \\
5 \\
3 \\
3 \\
3 \\
3 \\
3 \\
3\end{array}$ & $\begin{array}{r}5 \\
5 \\
5 \\
5 \\
5 \\
5 \\
5 \\
5 \\
10 \\
10 \\
10 \\
15 \\
15 \\
15 \\
9 \\
9 \\
9 \\
12 \\
12 \\
12 \\
\end{array}$ & $\begin{array}{l}0.375 \\
0.375 \\
0.375 \\
0.375 \\
0.375 \\
0.375 \\
0.375 \\
0.375 \\
0.375 \\
0.375 \\
0.375 \\
0.375 \\
0.375 \\
0.375 \\
0.375 \\
0.375 \\
0.375 \\
0.375 \\
0.375 \\
0.375\end{array}$ & $\begin{array}{l}7,486 \\
7,486 \\
7,486 \\
7,486 \\
7,486 \\
7,486 \\
7,486 \\
7,486 \\
7,486 \\
7,486 \\
7,486 \\
7,486 \\
7,486 \\
7,486 \\
7,486 \\
7,486 \\
7,486 \\
7,486 \\
7,486 \\
7,486\end{array}$ & $\begin{array}{l}20.23 \\
19.37 \\
20.12 \\
19.71 \\
19.89 \\
48.13 \\
41.82 \\
42.44 \\
42.13 \\
44.53 \\
44.03 \\
68.99 \\
68.39 \\
68.99 \\
16.59 \\
15.90 \\
14.71 \\
22.17 \\
21.62 \\
22.54\end{array}$ \\
\hline \multicolumn{6}{|c|}{ (b) Humphreys, R., 1957: Reinforced Beam } \\
\hline $\begin{array}{l}\text { PIA } \\
\text { PIB } \\
\text { PIC } \\
\text { PID } \\
\text { PIE } \\
\text { PRIA } \\
\text { PRIB } \\
\text { PRIC } \\
\text { PSIA } \\
\text { PSIB } \\
\text { PSIC } \\
\text { PTIA } \\
\text { PTIB } \\
\text { PTIC } \\
\text { PUIA } \\
\text { PUIB } \\
\text { PUIC }\end{array}$ & $\begin{array}{l}5 \\
5 \\
5 \\
5 \\
5 \\
5 \\
5 \\
5 \\
5 \\
5 \\
5 \\
3 \\
3 \\
3 \\
3 \\
3 \\
3\end{array}$ & $\begin{array}{r}5 \\
5 \\
5 \\
5 \\
5 \\
5 \\
10 \\
10 \\
10 \\
10 \\
15 \\
9 \\
9 \\
9 \\
9 \\
9 \\
9\end{array}$ & $\begin{array}{l}0.375 \\
0.375 \\
0.375 \\
0.375 \\
0.375 \\
0.375 \\
0.375 \\
0.375 \\
0.375 \\
0.375 \\
0.375 \\
0.375 \\
0.375 \\
0.375 \\
0.375 \\
0.375 \\
0.375\end{array}$ & $\begin{array}{l}7,486 \\
7,486 \\
7,486 \\
7,486 \\
7,486 \\
7,486 \\
7,486 \\
7,486 \\
7,486 \\
7,486 \\
7,486 \\
7,486 \\
7,486 \\
7,486 \\
7,486 \\
7,486 \\
7,486\end{array}$ & $\begin{array}{l}19.76 \\
21.53 \\
22.23 \\
21.16 \\
19.29 \\
44.77 \\
46.13 \\
45.82 \\
74.09 \\
73.59 \\
72.09 \\
16.44 \\
15.44 \\
14.92 \\
24.61 \\
21.14 \\
22.11\end{array}$ \\
\hline
\end{tabular}

account by coefficient $C_{1}$ in Eq. 5 , which is only approximate and is the source of large additional errors.

Figs. 3-6 also show by the dashed lines the size effect according to linear elastic fracture mechanics. It is obvious that, with the exception of Fig. 4, this effect is much too strong.
TABLE 1. Conilinued

\begin{tabular}{|c|c|c|c|c|c|}
\hline $\begin{array}{c}\text { Beam } \\
\text { number } \\
\text { (1) }\end{array}$ & $\begin{array}{l}b \\
\text { (in.) } \\
(2)\end{array}$ & $\begin{array}{c}d \\
\text { (in.) } \\
(3)\end{array}$ & $\begin{array}{l}d_{a} \\
\text { (in.) } \\
\text { (d) }\end{array}$ & $\begin{array}{c}f_{c}^{\prime} \\
\text { (psi) } \\
(5)\end{array}$ & $\begin{array}{c}T_{*} \\
(k \mid p-\ln .) \\
(6)\end{array}$ \\
\hline \multicolumn{6}{|c|}{ (c) McMullen and Daniel, 1975: Reinforced Beam } \\
\hline $\begin{array}{l}\text { B1 } \\
\text { B75 } \\
\text { B77 } \\
\text { B5 } \\
\text { B6 } \\
\text { B14 } \\
\text { B38 } \\
\text { B39 }\end{array}$ & $\begin{array}{r}22 \\
22 \\
22 \\
7 \\
7 \\
7 \\
3 \\
3\end{array}$ & $\begin{array}{l}10 \\
10 \\
10 \\
10 \\
10 \\
10 \\
10 \\
10\end{array}$ & $\begin{array}{l}0.5 \\
0.5 \\
0.5 \\
0.5 \\
0.5 \\
0.5 \\
0.5 \\
0.5\end{array}$ & $\begin{array}{l}6,450 \\
6,150 \\
6,640 \\
5,730 \\
5,730 \\
5,730 \\
5,850 \\
5,380 \\
\end{array}$ & $\begin{array}{r}266 \\
237 \\
260 \\
56 \\
46 \\
56 \\
16 \\
14 \\
\end{array}$ \\
\hline \multicolumn{6}{|c|}{ (d) Hsu, T.T.C., 1968: Unreinforced Beam } \\
\hline $\begin{array}{l}\text { A1 } \\
\text { A2 } \\
\text { A3 } \\
\text { A4 } \\
\text { A5 } \\
\text { A6 } \\
\text { A7 } \\
\text { A8 } \\
\text { A9 } \\
\text { A10 }\end{array}$ & $\begin{array}{l}10 \\
10 \\
10 \\
10 \\
10 \\
10 \\
6 \\
6 \\
6 \\
6\end{array}$ & $\begin{array}{l}15 \\
15 \\
10 \\
10 \\
20 \\
20 \\
11 \\
11 \\
19.5 \\
19.5\end{array}$ & $\begin{array}{l}0.75 \\
0.75 \\
0.75 \\
0.75 \\
0.75 \\
0.75 \\
0.75 \\
0.75 \\
0.75 \\
0.75\end{array}$ & $\begin{array}{l}4,060 \\
4,060 \\
4,000 \\
4,120 \\
4,230 \\
4,160 \\
3,920 \\
4,260 \\
4,470 \\
3,860\end{array}$ & $\begin{array}{c}162 \\
169 \\
102 \\
100 \\
216 \\
216 \\
54 \\
56.5 \\
101 \\
85\end{array}$ \\
\hline
\end{tabular}

\section{Conclusion}

1. The existing test data on torsional failure of unreinforced and longitudinally reinforced concrete beams of rectangular cross section without stirrups indicate that a size effect is present, i.e., the nominal stress at failure decreases as the cross section size increases.

2. Although the existing lest data confirm that a size effect is present, their size range is so narrow and their scatter is so large that the precise form of the size effect cannot be identified. Nevertheless, the existing data do not disagree with the size effect law for failures due to distributed cracking which was previously derived theoretically, based on fracture mechanics arguments.

3. The existing data indicate that the size effect is on the average weaker than linear elastic fracture mechanics predicts.

4. In view of the lack of geometrical similarity and the serious size-range limitation of the existing data, further tests that would be geometrically similar and would cover a much broader size range are desirable.

\section{ACKNOWLEDGMENT}

Partial financial support for developing the theoretical background was provided under AFOSR Grant No. 83-0(K)9 to Northwestern University. 


\section{Appendix. References}

1. Andersen, P., "Rectangular Concrete Sections under Torsion," ACI Journal, Vol. 34, No. 1, Sept.-Oct., 1937, pp, 1-11

2. Bach, B., and Graf, O., "Versuche uber die Widerstandsfähigkeit von Beton und Eisenbeton gágen Verdrehung (Investigation of Torsional Strength of Concrete and Reinforced Concrete)," Deutscher Ausschuss für Eisenbeton, Heft 16, Wilhelm Ernst, Berlin, Germany, 1912

3. Bažant, Z. P., "Size Effect in Blunt Fracture: Concrete, Rock, Metal," Journal of Engineering Mechanics, ASCE, Vol. 110, Apr., 1984, pp. 518-535.

4. Bažant, Z. P., "Mechanics of Fracture and Progressive Cracking in Concrete Structures," Fracture Mechanics Applied to Engineering Problems, Chap. 1, G. C. Sih and A. DiTomasso, eds., Martinus Nijhoff Publishers, The Hague, Netherlands, 1984, pp. 1-94.

5. Bazant, Z. P., "Mechanics of Distributed Cracking." ASME Applied Mechanics Reviews, Vol. 39, No. 5, 1986, pp. 675-705.

6. Bažant, Z. P., "Fracture Mechanics and Strain-Softening of Concrete," Proceedings, U.S.-Japan Seminar on Finite Element Analysis of Reinforced Concrete, May, 1985, Japan Concrete Institute, Tokyo, Japan, (published by ASCE, C. Meyer and H. Okamura eds., New York, N.Y., pp. 25-47).

7. Bažant, Z. P., "Fracture in Concrete and Reinforced Concrete," Mechanics of Geomaterials: Rocks, Concretes, Soils, Chap. 13, Z. P. Bażant, ed., John Wiley \& Sons, New York, N.Y., 1985, pp. 259-304.

8. Bažant, Z. P., "Fracture Energy of Heterogeneous Material and Similitude," Preprints, June 1987 SEM-RILEM International Conference on Fracture of Concrete and Rock, held at Houston, Texas, S. P. Shah and S. Swartz, eds., Sociely for Experimental Mechanics, pp. $390-402$.

9. Bazant, Z. P., and Cao, Z., "Size Effect in Shear Failure of Prestressed Concrete Beams," ACl Journal, Vol. 83, No. 2, March-April, 1986, pp. 260-268.

10. Bažant, Z. P., and Cao, Z., "Size Effect in Britlle Failure of Unreinforced Pipes," ACl Journal, Vol. 83, No. 3, May-June, 1986, pp. 369-373.

11. Bazant, Z. P., and Cao, Z., "Size Effect in Punching Shear Failure of Slabs," ACI Siructural Journal, Vol. 84, Jan.-Feb. 1987, pp. 44-53.

12. Bazant, Z. P., and Kim, J. K., "Size Effect in Shear Failure of Reinforced Concrete Beams," ACI Journal, Vol. 81, Sept., 1984, pp. 456-468, with discussion by K. D. Chin, Vol. 82, July, 1985, pp. $579-583$.

13. Bažant, Z. P., and Şener, S., "Effect of Aggregate Size in Shear Failure of Reinforced Concrete Beams," Internal Report, Center for Concrete \& Geomaterials, Northwestern University, Evanston, III., May, 1985 (used as basis for discussion closure of Ref. 12).

14. "Commentary on Building Code Requirements for Reinforced Concrete (ACI 318M-83)," ACl Standard, ACI, June, 1984.

15. Cowan, H. J., "Tests of Torsional Strength and Deformation of Rectangular Reinforced Concrete Beams," Concrete and Constructional Engineering, Vol. 46, No. 2, London, U.K., 1951, pp. 51-59

16. Cowan, H. J., and Armstrong, S., "Experiments on the Strength of Reinforced and Prestressed Concrete Beams and of Concrete-Encased Steel Joints in Combined Bending and Torsion," Magazine of Concrete Research. Vol. 6, No. 19, 1955, pp. 3-20.

17. Ernest, G. C., "Utimate Torsional Properties of Rectangular Reinforced Concrete Beams," ACl Journal, Vol. 29, No. 4, 1957, pp. 341-356.

18. Hsu, T. T. C., "Torsion of Structural Concrete-Plain Concrete Rectangular Sections," Torsion of Structural Concrete (SP-18), American Concrete Institute, Detroit, Mich., 1968, pp. 203-238.

19. Hsu, T. T. C., Torsion of Reinforced Concrete, Van Nostrand Reinhold Co., New York, N.Y., 1984, 516 pages.

20. Humphreys, R., "Torsional Properties of Prestressed Concrete," Structural
Engineer, Vol. 35. No. 6, London, U.K., 1957, pp. 213-224.

21. Kemp, E. L., Sozen, M. A., and Siess, C. P., "Torsion in Reinforced Concrete" Report No. 226, Department of Civil Engineering, University of Illinois at Urbana-Champain, Sept., 1961.

22. Marshall, W. T., and Tempe, N. R.. "Experiments on Plain and Reinforced Concrele in Torsion," Siructural Engincer, Vol. 19, No. 11, London, U.K., 1941, pp. 177-191.

23. McMullen, A. E., and Daniel, H. R., "Torsional Strength of Longitudinally Reinforced Beams Containing an Opening," $A C I$ Journal, Vol. 72 , No. 8, 1975, pp. 415-420.

24. Mukherjec, P. R., "Ultimate Torsional Strength of Plain, Prestressed and Reinforced Concrete Members of Rectangular Cross-Section." thesis presented to West Virginia University, at Morgantown, W. Va., in 1967, in partial fulfillment of the requirements for the degree of Doctor of partial fulfill

25. Mukherjee, S. K., "Torsional Strength and Stiffness of Rectangular Plain and Reinforced Lightweight Aggregate Concrete Members," thesis presented to West Virginia University, at Morgantown, W. Va., in 1972, in partial fulfillment of the requirements for the degree of Doctor of Philosophy.

26. Neville, A. M. Properties of Concrete, 2 nd ed., John Wiley \& Sons, New York, N.Y., 1973, 686 pages.

27. Park, P., and Paulay, T., Reinforced Concrete Siructures, John Wiley \& Sons, New York, N.Y., 1975, 769 pages.

28. Sundra, K. T., Iyengar, R., and Rangan, B. V., "Strength and Stiffness of Reinforced Concrete Beams under Combined Bending and Torsion," Torsion of Siructural Concrete (SP-18), American Concrete Institute, Detroit, Mich., 1968, pp. 403-440.

29. Turner, L., and Davies, V. C., "Plain and Reinforced Concrete in Torsion, with Particular Reference to Reinforced Concrete Beans," Institution of Civil Enginecrs, London, U.K. (Selected Engincering Papers No. 165).

30. Victor, D. J., "Eeffective Flange Width in Torsion," ACI Journal. Vol. 68. No. 1, 1971, pn. 42-46.

31. Victor, D. J., and Muthukrishnan, R., "Effect of Stirrups on Ultimate Torque of Reinforced Concrete Beams," ACl Journal, Vol. 70, No. 4, Apr., 1973, pp. 300-306.

32. Young, C. R., Sagar, W. L.., and Hughes, C. A., "Torsional Strength of Rectangular Sections of Concrete, Plain and Reinforced," Bulletin No. 9. School of Enginecring. University of Toronto, 1922.

33. Youssef, M. A. R., and Bishara, A. G., "Dowel Action in Concrete Beams Subject to Torsion," Journal of the Structural Division, ASCE, Vol. 106. No. 6, 1980, pp. 1263-1277.

34. Zia, P., "Torsional Strength of Concrete Members," ACl Journal, Vol. 57. No. 58,1961, pp. 1337-1359. 